\title{
Biodiversity of arbuscular mycorrhizal fungi of pumpkins (Cucurbita spp.) under the influence of fertilizers in ferralitic soils of Cameroon and Benin
}

\author{
Judith Taboula Mbogne ${ }^{1,2}$, Carine Nono Temegne ${ }^{1,4}$, Pascal Hougnandan ${ }^{2}$, Emmanuel Youmbi $^{1,3^{*}}$, Libert Brice \\ Tonfack $^{1,5}$, Godswill Ntsomboh-Ntsefong ${ }^{1,6}$ \\ ${ }^{1}$ The University of Yaounde I. Faculty of Science. Department of Plant Biology. Laboratory of Biotechnologies and Environement. Physiology and \\ Breeding Unit. P.O.BOX 812 Yaounde, Cameroon. ${ }^{2}$ University of Abomey-Calavi. Faculty of Agricultural Science. Department of Plant Biology. \\ Laboratory of Soil Microbiology and Microbial Ecology. P.O. BOX 711 Abomey-Calavi, Cotonou, Benin. ${ }^{3}$ African Centre of Research on Banana and \\ Plantain (CARBAP), Njombe. P.O. BOX 832 Douala, Cameroon. ${ }^{4}$ University of Bamenda. Higher Technical Teacher Training College. Department of \\ Civil Engineering and Forestry Techniques-Agricultural Education. P.O.BOX 39 Bambili, Cameroon. ${ }^{5}$ University of Pretoria. Forest and Agricultural \\ Biotechnology Institute. ${ }^{6}$ Institute of Agricultural Research for Development (IRAD-CEREPAH) of La Dibamba, Cameroon.
}

\begin{tabular}{l} 
ARTICLE INFO \\
\hline Article history: \\
Received on: 07/06/2015 \\
Revised on: $17 / 07 / 2015$ \\
Accepted on: 04/08/2015 \\
Available online: $22 / 10 / 2015$ \\
\hline Key words: \\
Cucurbita spp., arbuscular \\
mycorrhizal fungi, \\
biodiversity, fertilizer \\
application, Benin, \\
Cameroon.
\end{tabular}

\begin{abstract}
In Africa, many people suffer from nutrient deficiencies and this enhances the need for yield increase of crops like pumpkins with good nutritional qualities, while safeguarding the environment. The aim of this study was to assess the composition and specific diversity of arbuscular mycorrhizal fungi (AMF) in the rhizosphere of pumpkins under two fertilizer application systems. The experiment was conducted with a completely randomized design with a split-plot of three factors: fertilizers, pumpkin varieties and experimental sites. Dried seeds of pumpkin were sown after field preparation and at flowering and fruiting, samples of soil and root fragments were collected from the rhizosphere. In the laboratory, roots were clarified and coloured before microscopic observations. Soil samples were used for the extraction of spores through humid filtering. Spore suspension was poured into a Petri dish and spores counted with the help of a stereo microscope. The spores of AMF were identified on the basis of morphological descriptions. Results show that chemical fertilizer (T2) significantly reduces $(\mathrm{p}<0.001)$ the frequency and intensity of mycorrhization compared with control (T0) and fowl droppings (T1). The hierarchical classification shows two classes $\left(\mathrm{R}^{2}=0.63\right)$ : $\mathrm{T} 0$ and $\mathrm{T} 1$; and $\mathrm{T} 2$. Some 15 AMF species of four genera were isolated and identified. Of these, Glomus (57.97-85.65\%) and Acaulospora (12.68$40.42 \%$ ) were the most abundant with high density (1086 spores/100 $\mathrm{g}$ of soil). Glomus intraradices was absent in Benin and present in Cameroon. Diversity indices were higher in Cameroon than in Benin.
\end{abstract}

\section{INTRODUCTION}

More than 800 million people in the world and more particularly in sub Saharan Africa are undernourished and suffer from insufficient energy intake associated with deficiency in proteins, vitamins and mineral elements 1 . In the developing world, life span does not exceed 50 years and malnutrition is the cause of half the number of deaths of children below 5 years of age 1 . In addition, the world population is projected to increase

\section{* Corresponding Author}

Emmanuel Youmbi, The Universityof Yaounde I. Faculty of Science. Department of Plant Biology. Laboratory of Biotechnologies and Environement. Physiology and Breeding Unit. P.O.BOX 812 Yaounde Cameroon.Email: youmbi_emmanuel@yahoo.fr beyond agricultural production. Agricultural research is therefore challenged to improve on food security through improved crop yields and soil productivity, while safeguarding the environment. Within this framework, pumpkins (Cucurbita spp.) can play an important role since its fruits and leaves are rich in vitamins, minerals and fibers etc. 2. Moreover, pumpkin is an excellent source of vitamin A; its orange color indicates the presence of beta carotene which the organism can transform into vitamin A 3 . However, crop yields, particularly those of pumpkins in the countries of sub Saharan Africa are amongst the least in the world. Low yields in rural areas are due to plant diseases, poor cultural practices, pests and especially reduction in soil fertility 4 . The role of soil micro-organisms such as mycorrhizal fungi has been 
demonstrated in the development of sustainable agriculture 56 . Mycorrhizae are symbiotic associations between plant roots and mycelial filaments of soil fungi which favor plant growth and development 7. Many plant species directly depend on AMF for survival 8. AMF, particularly Endomycorrhizas form associations with approximately 80 percent of all plant species. These fungi cannot be grown in pure culture but must be grown in association with plant roots. Thus they cannot be multiplied on artificial media without a living host 9. They form branched structures called arbuscules within the host's root cells, and thus are known as arbuscular mycorrhizal fungi. The arbuscules are sites of nutrient exchange between the fungus and the host 10 .

Despite their importance, these fungi are not exploited and are almost ignored by African farmers. Studies in the humid forest of south Cameroon have shown that most forest species and cultivated plants are highly mycotrophic in their natural habitats 1112. So far, there is no information on mycotrophic species of cultivated pumpkins. Moreover, little data exists on endomycorrhiza biodiversity under pumpkin culture with respect to type of fertilizer used. For these reasons, this work was aimed at studying the biodiversity of endomycorrhiza fungi associated with pumpkin cultivation under the effect of fertilizers in Cameroon and Benin.

\section{MATERIAL AND METHODS}

\subsection{Study sites}

The experiment was undertaken during the 2012 and 2013 cropping seasons in Benin and Cameroon. In Cameroon, it was carried out at Mbalgong situated at $11^{\circ} 22^{\prime} 59^{\prime \prime}$ longitude East and $3^{\circ} 46$ ' 59 ' latitude North. The climate of this locality is of the equatorial Guinean type with an average atmospheric temperature of $23{ }^{\circ} \mathrm{C}$. It has four seasons: two rainy and two dry seasons. Annual rainfall is $1800 \mathrm{~mm}$. Average humidity is $80 \%$, with daily variation between 35 and $98 \%$. The preceding plants on the experimental site were cassava (Manihot esculenta Crantz) and predominant species like Chromolaena odorata (L.), Mimosa pudica (L.), and Imperata cylindrica (L.).

In Benin, the experiment was realized in the "Ferme d'Application et de Production (FAP)" of the Faculty of Agricultural Sciences of the University of Abomey-Calavi (FSA). With reference to information obtained from INSAE [Institut National de la Statistique et de l'Analyse Economique. Cahier de villages et de quartiers de ville - Département de l'Atlantique. Cotonou: 2004], the altitude of the locality is $17.4 \mathrm{~m} ; 06^{\circ} 24 \mathrm{~N}$, $\left.02^{\circ} 20 \mathrm{E}\right)$. The climate at FAP is the sub Equatorial type marked by two dry and two rainy seasons. The relief is less accidental and annual rainfall in the locality varies between 900 and $1100 \mathrm{~mm}$. Relative humidity varies between 55 and $95 \%$ and annual sunshine is about $2024 \mathrm{~h}$. Average temperature is $27{ }^{\circ} \mathrm{C}$. The site was formerly a fallow dominated by Panicum maximum (Jacq.). Physico-chemical analysis of soil from Mbalgong was done in the laboratories of IITA (International Institute for Tropical Agriculture) in Nkolbisson (Cameroon) and Abomey-Calavi at
INRAB (National Institute of Agricultural Research of Benin) Agonkanmey in Benin.

\subsection{Biological Materials}

Three varieties of squashes (pumpkin) were used for the experimentation; two of Cucurbita moschata variety (V2: straight neck and V3: egg shaped) and one Cucurbita maxima (V1: round shape) (Figure 1). Matured grains were obtained from fruits of the different varieties harvested from the farms of peasants. The grains were dried under sunlight for one month.
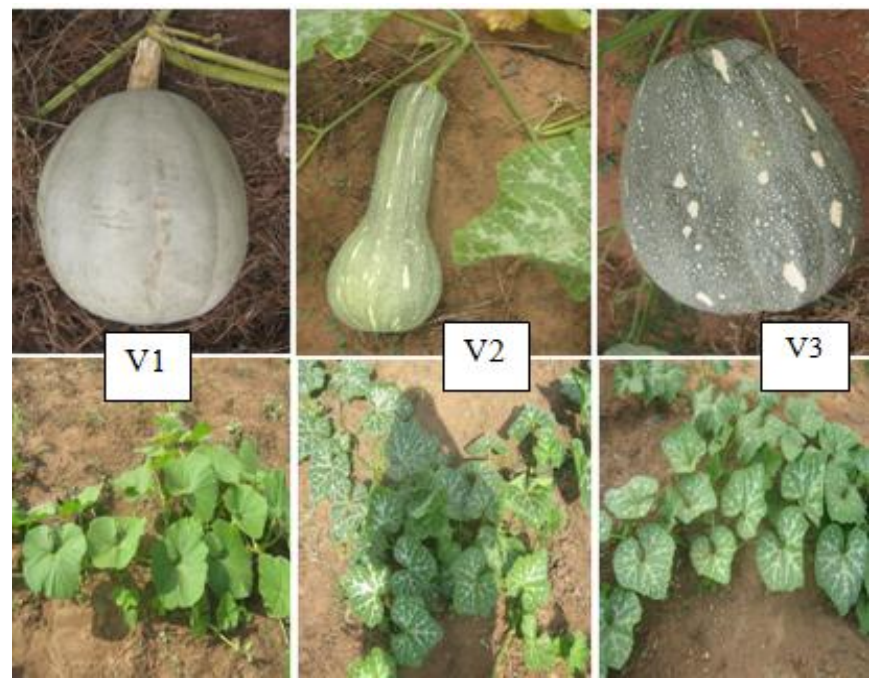

Fig. 1: Varieties of squashes (pumpkin) used for the experimentation. Cucurbita moschata variety (V2: straight neck and V3: egg shaped) and one Cucurbita maxima (V1: round shape).

\subsection{Fertilizers}

Two types of fertilizers were used in this study: organic fertilizer (fowl droppings) and chemical fertilizer. Eight months old fowl droppings were obtained from poultries and used to treat experimental plots at the rate of $20 \mathrm{t} / \mathrm{ha} 13$, thus $32 \mathrm{~kg}$ for a plot of $16 \mathrm{~m}^{2}$. The manure was buried in the soil two weeks before seeds were sown. The chemical fertilizer was used to balance cationic charges and nutritive elements of the soil with respect to plant needs. With reference to physicochemical characteristics of the soil in Benin, $10.4 \mathrm{~g}$ magnesium oxide $(\mathrm{MgO}), 505.6 \mathrm{~g}$ potassium chloride $(\mathrm{KCl} 60 \%), 339 \mathrm{~g}$ urea $(46 \%)$ and $1.5 \mathrm{~g}$ of triple superphosphate (TSP $42 \%$ ) were applied. In Cameroon $1.48 \mathrm{~kg}$ of potassium sulfate (The potassium sulfate contains $50 \% \mathrm{~K}_{2} \mathrm{O}$ ), $0.226 \mathrm{~kg}$ kerserite $(25 \% \mathrm{MgO})$ and $2.24 \mathrm{~kg}$ of ammonium phosphate $\left(18 \% \mathrm{~N}+45 \% \mathrm{P}_{2} \mathrm{O}_{5}\right)$ were applied per experimental unit. Chemical fertilizer was applied two weeks after sowing with the exception of urea fertilizer application in Benin which was applied in fractions : $2 / 3$ two weeks after sowing and $1 / 3$ one and a half months later.

\subsection{Experimental procedure}

The experimental design for this study was a split-plot with three factors: fertilizers (T0: control, T1: fowl droppings, $\mathrm{T} 2$ : 
chemical fertilizer), pumpkin varieties (V1: Cucurbita maxima Duch., rounded form, V2 : Cucurbita moschata Duch., elongated form with straight neck and V3 : C. moschata, ovoid form) and experimental sites. The experiment in each site was organized in complete random blocks. After clearing and tillage, each plot of 51 $\mathrm{m} \times 23.5 \mathrm{~m}$ was divided into four parallel blocks of $51 \mathrm{~m} \mathrm{x} 4 \mathrm{~m}$ each per site. Spacing between experimental blocks was $1.5 \mathrm{~m}$. With the help of a double decameter, a string and pegs, nine experimental units of $4 \mathrm{~m} \times 4 \mathrm{~m}$ were constituted per block, making a total of 36 units per site. Two lines were made per plot and the space between pegs was $2 \mathrm{~m}$. The dried grains of pumpkin were sown (four grains per seed-hole) after field preparation. Two seedlings per seed-hole were eliminated after germination leaving a total of 288 plants per site. Care of experimental plots involved manual weeding, mulching around the plants and watering in the absence of rainfall.

\subsection{Sampling}

At flowering and fruiting, four samples each of soil and root fragments were collected from the rhizosphere of pumpkin seed-holes. For each experimental unit, the different soil samples were mixed to constitute a composite sample. About $5 \mathrm{~g}$ small roots attached to the main root were collected per seed-hole and conserved in $50 \%$ ethyl alcohol.

\subsection{Root colonization}

In the laboratory, roots were clarified and colored before microscopic observations 14. Selected root samples were rinsed with tap water and reduced to fragments 1-2 cm long. About $1 \mathrm{~g}$ of each pumpkin root sample was put into a test tube containing $10 \mathrm{~mL}$ of $\mathrm{KOH}(10 \%, \mathrm{~W} / \mathrm{V})$ for $24 \mathrm{~h}$. This action will empty the contents of their cytoplasmique cells while keeping intact fungal structures. These roots were later rinsed with tap water and soaked in $10 \mathrm{~mL}$ of oxygenated water $(10 \%)$ for $45 \mathrm{~min}$ in order to clarify and to oxidize the organic material present on the roots. After rinsing with water, the roots were soaked in $10 \mathrm{~mL}$ of trypan blue solution $(0.05 \%)$ which is a colorant. This solution is prepared using $333 \mathrm{ml}$ of glycerol, $333 \mathrm{ml}$ of lactic acid, $333 \mathrm{~mL}$ of distilled water and $0.5 \mathrm{~g}$ of trypan blue (powder) to $1 \mathrm{~L}$ of solution. The trypan blue solution gives a bluish tint to various infections to facilitate their identification under the microscope. After two to three days, the samples were prepared on glass slides and observed under an electron microscope.

\subsection{Isolation, enumeration and identification of AMF}

Using the method described by 15 , a $100 \mathrm{~g}$ soil sample from the pumpkin rhizophere was used for the extraction of spores through humid filtering via a series of sieve meshes between 425 and $432 \mu \mathrm{m}$. The suspension of spores in the sieves was centrifuged on a saccharose gradient at $50 \% 1617$. The suspension of spores was then poured into a Petri dish with crossruled surface to facilitate counting of spores with the help of a stereo microscope (Zeiss brand, magnification $\times 40$ ) with respect to their sizes, color and mode of attachment of hyphae to the spore.
The spores of AMF were mounted on glass slide in PVLG with Melzer reagent 19 and identified on the basis of morphological descriptions published by INVAM (http//www.invam.caf. wdu.edu) and BEG (European Bank of Glomales: http//www.bio. ukc.ac.uk.beg).

\subsection{Statistical analysis}

The AMF diversity of each site 20 was analyzed with the aid of the following indices: specific richness $(\mathrm{S}=$ number of species in the study zone), Shannon-Weiner (H') 21 diversity index and Pielou 22 equitability index. Shannon-Wiener index is calculated by the following formula:

$$
\mathrm{H}^{\prime}=-\sum_{i=1}^{s} P i \log P i
$$

where:

$\mathrm{Pi}$ : proportional abundance or percent importance of the species $(\mathrm{Pi}=\mathrm{ni} / \mathrm{N})$;

$\mathrm{S}$ : total number of species;

ni: number of individuals of a species in a sample;

$\mathrm{N}$ : total number of individuals of all species in a sample;

The equitability index is calculated using the following formula:

$\mathrm{J}$ '= H'/H'max with H'max $=\log \mathrm{S}(\mathrm{S}=$ total number of species $)$.

Data on the frequency and intensity of mycorrhization were treated by analysis of variance (ANOVA) using the SAS (Statistical Analysis Software). Student and Newman \& Keuls tests were used to compare means. Relationships between parameters were put into evidence by the Pearson correlation test. Data was also treated by analysis of principal components (ACP) using SAS.

\section{RESULTS}

\subsection{Soil properties of the study sites}

Soil analysis results are presented in table 1. The soil structure in Cameroon is limon-clay-sandy while in Benin it is limon-sandy. The $\mathrm{pH}$ of the soils were between 4 and 6 .

Table 1. Physico-chemical characteristics of the soils $(0-15 \mathrm{~cm}$ depth) of study sites.

\begin{tabular}{|c|c|c|c|}
\hline \multirow[b]{2}{*}{ Soil characteristics } & \multicolumn{2}{|c|}{ Study sites } & \\
\hline & $\begin{array}{c}\text { Abomey- } \\
\text { Calavi (Benin) }\end{array}$ & $\begin{array}{c}\text { Mbalgong } \\
\text { (Cameroon) }\end{array}$ & \\
\hline Sand $(\%)$ & $78.682 * * *$ & 58.232 & $\mathrm{p}<0.001$ \\
\hline Clay (\%) & 12.083 & $31.490 * * *$ & $\mathrm{p}<0.001$ \\
\hline Limon (\%) & 7.000 & $10.280^{* *}$ & $\mathrm{p}<0.005$ \\
\hline $\mathrm{C}(\%)$ & 0.68 & $1.880 * * *$ & $\mathrm{p}<0.001$ \\
\hline $\mathrm{OM}(\%)$ & 1.17 & $2.680 * * *$ & $\mathrm{p}<0.001$ \\
\hline $\mathrm{pH}$ & $6.060 \mathrm{~ns}$ & $4.900 \mathrm{~ns}$ & $\mathrm{p}>0.226$ \\
\hline $\mathrm{N}$ total $\left(\mathrm{g} \cdot \mathrm{kg}^{-1}\right)$ & 0.620 & $2.190 * * *$ & $\mathrm{p}<0.001$ \\
\hline Apparent soil density $\left(\mathrm{kg} \cdot \mathrm{dm}^{-3}\right)$ & $1.180 * * *$ & 0.755 & $\mathrm{p}<0.001$ \\
\hline $\mathrm{Ca}^{2+}\left(\mathrm{g} \cdot \mathrm{kg}^{-1}\right)$ & 0.227 & $0.741 * * *$ & $\mathrm{p}<0.001$ \\
\hline $\mathrm{K}^{+}\left(\mathrm{g} \cdot \mathrm{kg}^{-1}\right)$ & 0.022 & $0.055^{* * *}$ & $\mathrm{p}<0.001$ \\
\hline $\mathrm{P}\left(\mathrm{g} \cdot \mathrm{kg}^{-1}\right)$ & $0.498 * * *$ & 0.006 & $\mathrm{p}<0.001$ \\
\hline $\mathrm{Mg}^{2+}\left(\mathrm{g} \cdot \mathrm{kg}^{-1}\right)$ & 0.058 & $0.102 * * *$ & $\mathrm{p}<0.001$ \\
\hline $\mathrm{Na}^{+}\left(\mathrm{g} \cdot \mathrm{kg}^{-1}\right)$ & $0.053 * * *$ & 0.023 & $\mathrm{p}<0.001$ \\
\hline $\mathrm{C} / \mathrm{N}$ & $11.30 * * *$ & 8.59 & $\mathrm{p}<0.001$ \\
\hline
\end{tabular}

*: significant difference, $* *$ : highly significant difference, $* * *$ : very high significant difference, $\mathrm{ns}$ : non-significant, $\mathrm{pH}$ : potential of hydronium ion, $\mathrm{C}$ $\%$ : proportion of total organic carbon, $\mathrm{N}$ total : proportion of total nitrogen, $\mathrm{C} / \mathrm{N}$ : ratio between proportions of total organic carbon and total nitrogen, $\mathrm{OM}$ $\%$ : organic matter content, $\mathrm{P}$ : total phosphorus, $\mathrm{Ca}^{2+}$ : calcium content, $\mathrm{Mg}^{2+}$ : magnesium content, $\mathrm{K}^{+}$: potassium content, $\mathrm{Na}^{+}$: sodium content. 


\subsection{AMF colonization}

Mycorrhizal structures observed in pumpkin roots are in the form of arbuscules, vesicles, hyphae, spores and axillary bodies (Figure 2).

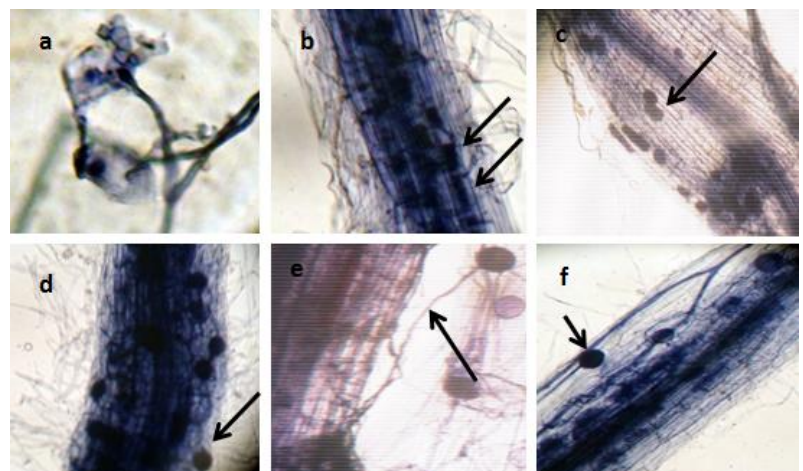

Fig. 2: Mycorrhizal structural colonization in Cucurbita spp. a: auxiliary cells; b: arbuscules; c,f: vesicles ; d : spores and e: hyphae.

\subsection{Frequency and intensity of mycorrhization}

Chemical fertilizer significantly $(\mathrm{p}<0.001)$ reduces the frequency of AMF as compared to the control (T0) and fowl droppings (T1) at flowering and fruiting of all pumpkin varieties (Figure 3). Whatever the kind of fertilizer used, the site does not influence the rate of mycorrhization in pumpkin culture. Moreover, the variety of pumpkin does not influence the frequency of mycorrhization.

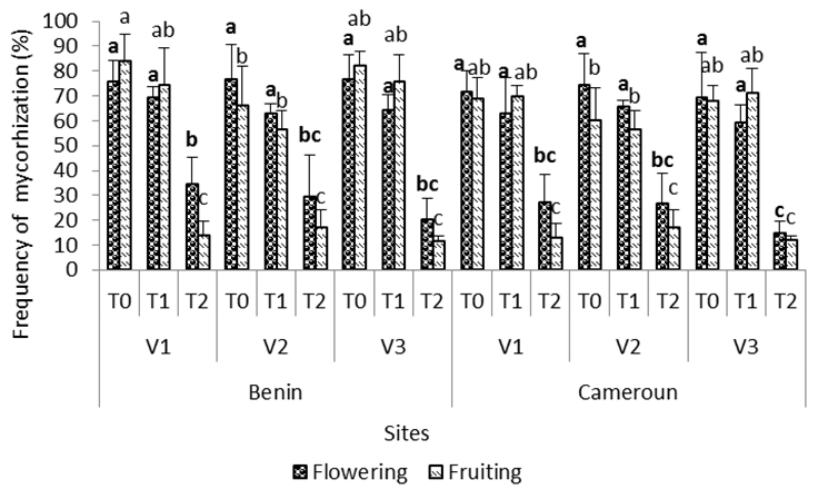

Fig. 3: Frequency of mycorrhization with respect to type of fertilizer application in Cucurbita sp. cultivation. V1 : Cucurbita maxima; V2 : Cucurbita moschata elongated shape; V3: C. moschata egg-shaped ; T0 : control; T1 : fowl droppings; T2: chemical fertilizers. For each stage of growth, the means with the same letter are not significantly different at $\mathrm{p}<0.05$.

Table 5 shows a highly significant correlation $(\mathrm{p}<0.001)$ between the frequency of mycorrhization and the number of spores of Gigaspora at fruiting. The intensity of mycorrhization is significantly $(\mathrm{p}<0.01)$ more important for T0 $\left(29.82 \pm 12.78 \%{ }^{\mathrm{a}}\right)$ than for T1 $\left(11.62 \pm 7.72 \%^{\mathrm{b}}\right)$ and T2 $\left(2.46 \pm 2.79 \%^{\mathrm{c}}\right)$ at flowering (Figure 4). The same observation was made at fruiting (T0: $27.89 \pm 12.92 \%^{\mathrm{a}}$; T1: $23.50 \pm 14.80 \%^{\mathrm{a}}$ and $\mathrm{T} 2: 0.45 \pm 0.62 \%^{\mathrm{b}}$ ). The study site does not influence the intensity of mycorrhization in pumpkin culture (Figure 4). The intensity of mycorrhization at flowering is strongly correlated to the number of spores of
Gigaspora while at fruiting; it is correlated to the number of spores of Acaulospora and Gigaspora (Table 5).

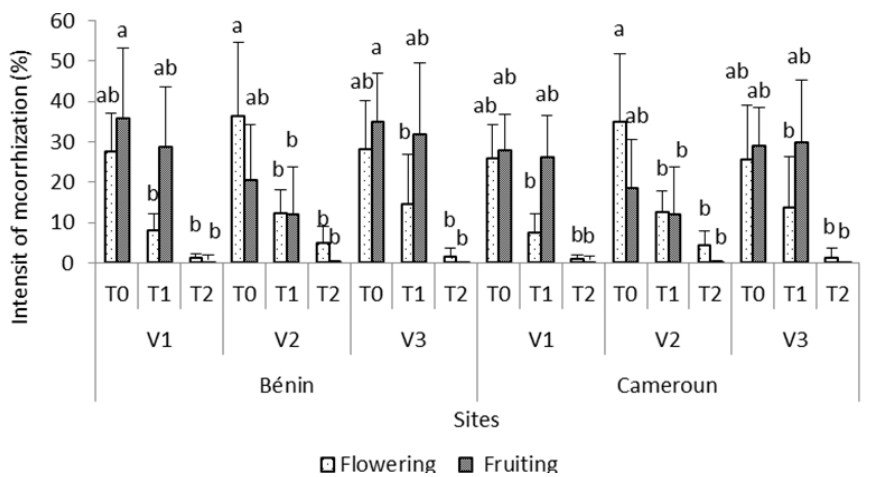

Fig. 4: Intensity of mycorrhization with respect to type of fertilizer application in Cucurbita spp. cultivation. V1 : Cucurbita maxima; V2 : Cucurbita moschata elongated shape ; V3 : C. moschata egg-shaped ; T0 : control ; T1 : fowl droppings ; T2 : chemical fertilizers. For each growth stage, the means with the same letter are not significantly different at $\mathrm{p}<0.05$.

\subsection{Identification of spores of mycorrhiza fungi}

The number of spores of AMF species is presented in table 2 while the images of some species are represented by Figure 5. All the spores of AMF found in the two sites belong to the phylum Glomeromycota (Table.3) according to the new classification by 23 . The 15 species (Table 3 ) identified possibly belong to three (3) different families: family Glomaceae, family Acaulosporaceae and family Gigasporaceae. With the exception of Glomus intraradices which is present only in Cameroon, the diversity of AMF is identical in the two sites. A signficant correlation $(\mathrm{p}<0.05)$ is observed between number of spores of the genera Glomus, Gigaspora and Scutellospora at flowering. On the contrary, at fruiting, the genus Scutellospora is not correlated to the three others which are correlated amongst themselves (Tab. 5).
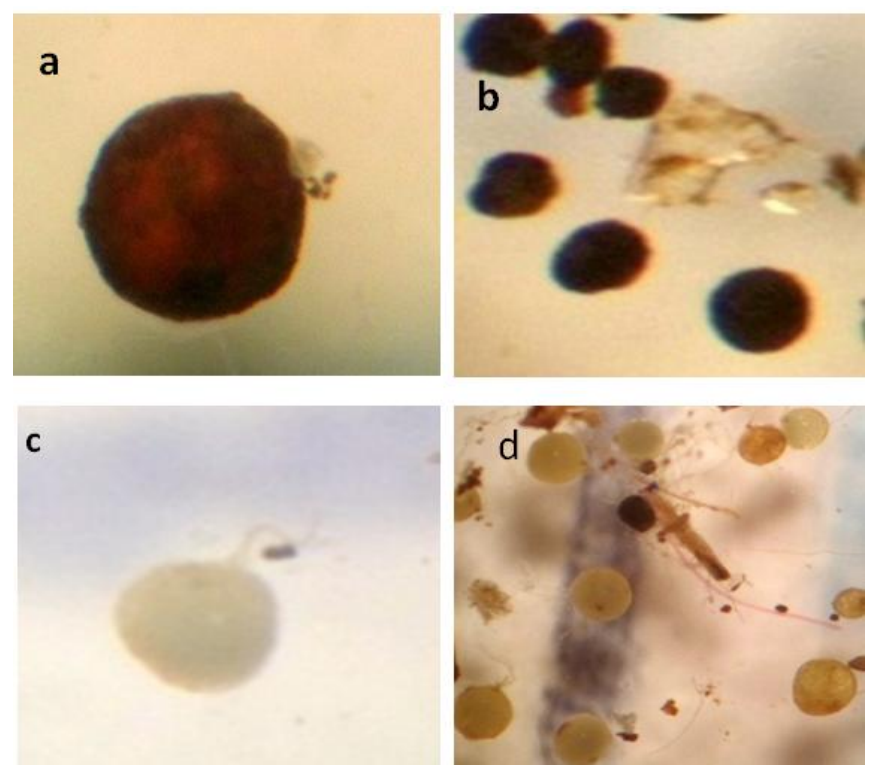

Fig. 5: AMF spores isolated from rhizosphere soil of Cucurbita spp. with fertilizer application. a: Scutellospora gregaria; b: Glomus constrictum and c $\&$ d: Gigaspora margarita. 
Table 2: Mean number of spores in $100 \mathrm{~g}$ of soil.

\begin{tabular}{|c|c|c|c|c|c|c|c|c|c|c|c|c|}
\hline \multirow{3}{*}{ AMF species } & \multicolumn{6}{|c|}{ Benin } & \multicolumn{6}{|c|}{ Cameroon } \\
\hline & \multicolumn{3}{|c|}{ Flowering } & \multicolumn{3}{|c|}{ Fruiting } & \multicolumn{3}{|c|}{ Flowering } & \multicolumn{3}{|c|}{ Fruiting } \\
\hline & T0 & $\mathrm{T} 1$ & $\mathrm{~T} 2$ & T0 & $\mathrm{T} 1$ & $\mathrm{~T} 2$ & T0 & $\mathrm{T} 1$ & $\mathrm{~T} 2$ & T0 & T1 & $\mathrm{T} 2$ \\
\hline G. constrictum & 612 & 626 & 620 & 1044 & 464 & 1086 & 562 & 576 & 570 & 1044 & 1032 & 1086 \\
\hline G. ambisporum & 7 & 8 & 8 & 10 & 5 & 17 & 4 & 6 & 7 & 7 & 6 & 6 \\
\hline G. manihotis & 31 & 35 & 26 & 55 & 10 & 26 & 31 & 33 & 28 & 57 & 56 & 41 \\
\hline G. caledonium & 3 & 3 & 2 & 0 & 0 & 0 & 3 & 3 & 2 & 3 & 2 & 1 \\
\hline G. geosporum & 116 & 109 & 94 & 130 & 57 & 108 & 111 & 104 & 89 & 126 & 125 & 107 \\
\hline G. intraradices & 0 & 0 & 0 & 0 & 0 & 0 & 15 & 17 & 14 & 29 & 28 & 20 \\
\hline Total ofGlomus & 770 & 781 & 750 & 1240 & 536 & 1237 & 727 & 739 & 709 & 1265 & 1248 & 1260 \\
\hline A.tuberculata & 14 & 19 & 17 & 33 & 7 & 35 & 10 & 11 & 11 & 42 & 30 & 49 \\
\hline A. rugosa & 10 & 9 & 9 & 92 & 27 & 72 & 6 & 6 & 5 & 76 & 74 & 51 \\
\hline A. delicata & 3 & 4 & 3 & 26 & 6 & 16 & 36 & 40 & 31 & 19 & 13 & 13 \\
\hline A. lacunosa & 135 & 189 & 212 & 237 & 95 & 212 & 134 & 186 & 209 & 204 & 171 & 176 \\
\hline A. colossica & 19 & 30 & 23 & 21 & 5 & 11 & 42 & 126 & 33 & 84 & 47 & 29 \\
\hline A. fovea & 2 & 3 & 2 & 1 & 0 & 2 & 4 & 4 & 2 & 3 & 2 & 2 \\
\hline Total of Acaulospora & 184 & 253 & 266 & 410 & 140 & 347 & 231 & 372 & 290 & 427 & 338 & 320 \\
\hline G. gigantea & 10 & 4 & 4 & 32 & 14 & 5 & 11 & 7 & 5 & 38 & 19 & 6 \\
\hline G. margarita & 1 & 2 & 1 & 13 & 3 & 2 & 4 & 3 & 2 & 12 & 7 & 3 \\
\hline Total of Gigaspora & 11 & 6 & 5 & 45 & 17 & 7 & 15 & 10 & 7 & 50 & 26 & 9 \\
\hline S. gregaria & 5 & 7 & 4 & 4 & 1 & 3 & 5 & 5 & 4 & 3 & 2 & 3 \\
\hline Total of Scutellospora & 5 & 7 & 4 & 4 & 1 & 3 & 5 & 5 & 4 & 3 & 2 & 3 \\
\hline
\end{tabular}

Table 3: Different AMF species found in the two study sites.

\begin{tabular}{|c|c|c|}
\hline Family & Genus & Species \\
\hline Glomeraceae & Glomus & $\begin{array}{l}\text { Glomus constrictum Trappe } \\
\text { G. ambisporum Smith \&Schenck } \\
\text { G. manihotis R.H. Howeler, Sieverd. \& N.C. Schenck } \\
\text { G. caledonium Nicolson \& Gerdemann } \\
\text { G. geosporum } \text { (Nicol. \& Gerd.) Walker } \\
\text { G. intraradices Schenck \& Smith* }\end{array}$ \\
\hline Acaulosporaceae & Acaulospora & $\begin{array}{l}\text { Acaulospora tuberculata Janos \& Trappe } \\
\text { A. rugosa J.B. Morton } \\
\text { A. delicata Walker, Pfeiffer \& Bloss } \\
\text { A. lacunosa Morton } \\
\text { A. colossica } \text { P.A. Schultz, Bever \& J.B. Morton } \\
\text { A. fovea }\end{array}$ \\
\hline \multirow[t]{2}{*}{ Gigasporaceae } & Gigaspora & $\begin{array}{l}\text { Gigaspora gigantean (Nicol. \& Gerd.) Gerd. \& Trappe } \\
\text { G. margarita Becker \& Hall }\end{array}$ \\
\hline & Scutellospora & Scutellospora gregaria (N.C. Schenck\& T.H. Nicolson) C. Walker \& F.E. Sanders \\
\hline Total & 4 & 15 \\
\hline
\end{tabular}

*: AMF species found only in Cameroon.

Table 4: AMF species richness and diversity indices in Cucurbita sp. under fertilizer application.

\begin{tabular}{|c|c|c|c|c|c|c|c|c|}
\hline \multirow[b]{3}{*}{ Zones } & \multirow[b]{3}{*}{ Variety } & \multirow[b]{3}{*}{ Fertilizer } & & & \multicolumn{4}{|c|}{ Diversity index } \\
\hline & & & \multicolumn{2}{|c|}{ (S) } & \multicolumn{2}{|c|}{ Shannon-Weiner(H') } & \multicolumn{2}{|c|}{ Piélou (E) } \\
\hline & & & Flowering & Fruiting & Flowering & Fruiting & Flowering & Fruiting \\
\hline \multirow{9}{*}{ Benin } & \multirow{3}{*}{ V1 } & T0 & $12.50 \pm 1.73 \mathrm{a}$ & $13.25 \pm 0.50 \mathrm{bc}$ & $1.85 \pm 0.18 b c$ & $1.64 \pm 0.26 b c$ & $0.51 \pm 0.70 b c$ & $0.44 \pm 0.07 \mathrm{~b}$ \\
\hline & & $\mathrm{T} 1$ & $12.50 \pm 1.00 \mathrm{a}$ & $13.50 \pm 1.00 \mathrm{~b}$ & $1.93 \pm 0.21 \mathrm{bc}$ & $1.77 \pm 0.08 \mathrm{bc}$ & $0.53 \pm 0.06 \mathrm{ab}$ & $0.47 \pm 0.08 b$ \\
\hline & & $\mathrm{T} 2$ & $14.00 \pm 0.00 \mathrm{a}$ & $13.00 \pm 0.00 \mathrm{bc}$ & $1.81 \pm 0.05 \mathrm{bc}$ & $1.41 \pm 0.03 c$ & $0.47 \pm 0.01 b c$ & $0.38 \pm 0.09 b$ \\
\hline & \multirow{3}{*}{$\mathrm{V} 2$} & T0 & $13.50 \pm 1.00 \mathrm{a}$ & $12.25 \pm 0.50 \mathrm{c}$ & $1.54 \pm 0.07 \mathrm{c}$ & $2.01 \pm 0.13 \mathrm{ab}$ & $0.41 \pm 0.01 \mathrm{c}$ & $0.55 \pm 0.03 \mathrm{ab}$ \\
\hline & & $\mathrm{T} 1$ & $14.00 \pm 0.00 \mathrm{a}$ & $12.75 \pm 0,50 \mathrm{bc}$ & $1.76 \pm 0.05 \mathrm{bc}$ & $1.98 \pm 0.02 \mathrm{ab}$ & $0.46 \pm 0.01 b c$ & $0.54 \pm 0.01 \mathrm{ab}$ \\
\hline & & $\mathrm{T} 2$ & $11.75 \pm 1.50 \mathrm{a}$ & $12.00 \pm 0.00 \mathrm{c}$ & $1.81 \pm 0.14 \mathrm{bc}$ & $1.63 \pm 0.02 b c$ & $0.51 \pm 0.04 b c$ & $0.45 \pm 0.05 \mathrm{~b}$ \\
\hline & \multirow{3}{*}{ V3 } & T0 & $13.50 \pm 0.57 \mathrm{a}$ & $13.00 \pm 0.00 \mathrm{bc}$ & $2.11 \pm 0.23 \mathrm{ab}$ & $2.13 \pm 0.08 \mathrm{ab}$ & $0.56 \pm 0.06 \mathrm{ab}$ & $0.57 \pm 0.02 \mathrm{ab}$ \\
\hline & & $\mathrm{T} 1$ & $13.00 \pm 1.15 \mathrm{a}$ & $13.00 \pm 0.00 \mathrm{bc}$ & $2.11 \pm 0.33 \mathrm{ab}$ & $1.81 \pm 0.39 b c$ & $0.57 \pm 0.10 \mathrm{ab}$ & $0.49 \pm 0.10 \mathrm{ab}$ \\
\hline & & $\mathrm{T} 2$ & $13.00 \pm 0.81 \mathrm{a}$ & $12.25 \pm 0.957 \mathrm{c}$ & $1.63 \pm 0.07 \mathrm{c}$ & $1.98 \pm 0.07 \mathrm{ab}$ & $0.44 \pm 0.02 b c$ & $0.55 \pm 0.01 \mathrm{ab}$ \\
\hline \multirow{9}{*}{ Cameroon } & \multirow{3}{*}{ V1 } & T0 & $14.00 \pm 1.41 \mathrm{a}$ & $15.00 \pm 0.00 \mathrm{a}$ & $2.17 \pm 0.18 \mathrm{ab}$ & $1.82 \pm 0.39 b c$ & $0.57 \pm 0.05 \mathrm{ab}$ & $0.46 \pm 0.09 \mathrm{~b}$ \\
\hline & & $\mathrm{T} 1$ & $14.25 \pm 0.95 a$ & $15.00 \pm 0.00 \mathrm{a}$ & $2.27 \pm 0.22 \mathrm{ab}$ & $1.87 \pm 0.13 b$ & $0.59 \pm 0.07 \mathrm{ab}$ & $0.47 \pm 0.03 b$ \\
\hline & & $\mathrm{T} 2$ & $15.00 \pm 0.00 \mathrm{a}$ & $14.75 \pm 0.50 \mathrm{a}$ & $2.09 \pm 0.11 \mathrm{~b}$ & $1.53 \pm 0.04 b c$ & $0.53 \pm 0.03 \mathrm{ab}$ & $0.39 \pm 0.01 \mathrm{~b}$ \\
\hline & \multirow{3}{*}{$\mathrm{V} 2$} & T0 & $14.75 \pm 0.50 \mathrm{a}$ & $15.00 \pm 0.00 \mathrm{a}$ & $1.98 \pm 0.09 b c$ & $2.14 \pm 0.19 \mathrm{ab}$ & $0.48 \pm 0.02 b c$ & $0.55 \pm 0.04 \mathrm{ab}$ \\
\hline & & $\mathrm{T} 1$ & $15.00 \pm 0.00 \mathrm{a}$ & $15.00 \pm 0.00 \mathrm{a}$ & $2.06 \pm 0.01 \mathrm{~b}$ & $2.18 \pm 0.04 \mathrm{ab}$ & $0.52 \pm 0.01 b$ & $0.55 \pm 0.01 \mathrm{ab}$ \\
\hline & & $\mathrm{T} 2$ & $13.75 \pm 0.95 \mathrm{a}$ & $13.25 \pm 0.50 \mathrm{bc}$ & $2.05 \pm 0.13 b$ & $1.71 \pm 0.24 b c$ & $0.54 \pm 0.02 \mathrm{ab}$ & $0.46 \pm 0.06 \mathrm{~b}$ \\
\hline & \multirow{3}{*}{ V3 } & T0 & $15.00 \pm 0.00 \mathrm{a}$ & $15.00 \pm 0.00 \mathrm{a}$ & $2.45 \pm 0.20 \mathrm{a}$ & $2.26 \pm 0.09 \mathrm{a}$ & $0.69 \pm 0.05 \mathrm{a}$ & $0.58 \pm 0.02 \mathrm{a}$ \\
\hline & & $\mathrm{T} 1$ & $14.25 \pm 0.95 \mathrm{a}$ & $14.50 \pm 0.57 \mathrm{a}$ & $2.14 \pm 0.35 \mathrm{ab}$ & $1.90 \pm 0.45 \mathrm{ab}$ & $0.56 \pm 0.08 \mathrm{ab}$ & $0.49 \pm 0.11 \mathrm{ab}$ \\
\hline & & $\mathrm{T} 2$ & $13.25 \pm 0.95 \mathrm{a}$ & $13.50 \pm 1.29 \mathrm{~b}$ & $1.85 \pm 0.14 b c$ & $2.05 \pm 0.19 \mathrm{ab}$ & $0.48 \pm 0.02 b c$ & $0.54 \pm 0.05 \mathrm{ab}$ \\
\hline
\end{tabular}

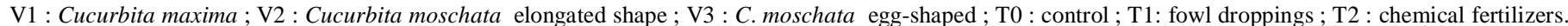
For each growth stage, the average with the same letter are not significantly different at $\mathrm{p}<0.05$. 
Table 5: Pearson correlation test between different parameters evaluated.

\begin{tabular}{|c|c|c|c|c|c|c|c|c|}
\hline & Glomus Fl & $\begin{array}{c}\text { Acaulo } \\
\text { sporaFl }\end{array}$ & $\begin{array}{c}\text { Giga } \\
\text { sporaFl }\end{array}$ & $\begin{array}{l}\text { Scutello } \\
\text { sporaFl }\end{array}$ & Glomus Fr & $\begin{array}{c}\text { Acaulo } \\
\text { spora Fr }\end{array}$ & $\begin{array}{c}\text { Giga } \\
\text { spora } \mathrm{Fr}\end{array}$ & $\begin{array}{c}\text { Scutellospora } \\
\text { Fr }\end{array}$ \\
\hline Glomus Fl & 1 & & & & & & & \\
\hline AcaulosporaFl & $0.147 \mathrm{~ns}$ & 1 & & & & & & \\
\hline GigasporaFl & $0.415 * * *$ & $0.065 \mathrm{~ns}$ & 1 & & & & & \\
\hline ScutellosporaFl & $0.706^{* * *}$ & $-0.039 \mathrm{~ns}$ & $0.371 * *$ & 1 & & & & \\
\hline Glomus Fr & $-0.021 \mathrm{~ns}$ & $0.364 * * *$ & $0.082 \mathrm{~ns}$ & $-0.085 n s$ & 1 & & & \\
\hline Acaulospora Fr & $-0.105 \mathrm{~ns}$ & $0.113 \mathrm{~ns}$ & $0.199 \mathrm{~ns}$ & $-0.185 n s$ & $0.496 * * *$ & 1 & & \\
\hline Gigaspora Fr & $-0.066 \mathrm{~ns}$ & $-0.188 n s$ & $0.256^{*}$ & $0.129 \mathrm{~ns}$ & $0.247 *$ & $0.328 * *$ & 1 & \\
\hline Scutellospora Fr & $0.003 \mathrm{~ns}$ & $-0.356 \mathrm{~ns}$ & $0.124 \mathrm{~ns}$ & $-0.037 \mathrm{~ns}$ & $-0.106 n s$ & $-0.006 n s$ & $0.062 \mathrm{~ns}$ & 1 \\
\hline H'Fl & $-0.423 * * *$ & $0.060 \mathrm{~ns}$ & $-0.045 \mathrm{~ns}$ & $-0.304 * *$ & $0.046 \mathrm{~ns}$ & $0.175 \mathrm{~ns}$ & $0.164 \mathrm{~ns}$ & $0.050 \mathrm{~ns}$ \\
\hline $\mathrm{EFl}$ & $-0.491 * * *$ & $0.021 \mathrm{~ns}$ & $-0.152 \mathrm{~ns}$ & $-0.395 * * *$ & $0.013 \mathrm{~ns}$ & $0.098 \mathrm{~ns}$ & $0.113 \mathrm{~ns}$ & $-0.001 \mathrm{~ns}$ \\
\hline $\mathrm{H}^{\prime} \mathrm{Fr}$ & $-0.078 \mathrm{~ns}$ & $-0.196 n s$ & $0.275^{*}$ & $-0.029 \mathrm{~ns}$ & $-0.563 * * *$ & $0.203 \mathrm{~ns}$ & $0.250^{*}$ & $0.093 \mathrm{~ns}$ \\
\hline E Fr & $-0.061 \mathrm{~ns}$ & $-0.253 *$ & $0.242 *$ & $-0.001 \mathrm{~ns}$ & $-0.618 * * *$ & $0.175 \mathrm{~ns}$ & $0.212 \mathrm{~ns}$ & $0.139 \mathrm{~ns}$ \\
\hline FM Fl & $0.055 \mathrm{~ns}$ & $-0.077 \mathrm{~ns}$ & $0.196 \mathrm{~ns}$ & $0.118 \mathrm{~ns}$ & $0.101 \mathrm{~ns}$ & $0.172 \mathrm{~ns}$ & $0.416 * * *$ & $0.011 \mathrm{~ns}$ \\
\hline FM Fr & $-0.123 n s$ & $-0.068 n s$ & $0.224 \mathrm{~ns}$ & $0.039 \mathrm{~ns}$ & $0.033 \mathrm{~ns}$ & $0.162 \mathrm{~ns}$ & $0.495 * * *$ & $0.036 \mathrm{~ns}$ \\
\hline IM Fl & $0.101 \mathrm{~ns}$ & $-0.088 n s$ & $0.316 * *$ & $0.110 \mathrm{~ns}$ & $0.101 \mathrm{~ns}$ & $0.189 \mathrm{~ns}$ & $0.499 * * *$ & $0.037 \mathrm{~ns}$ \\
\hline IM Fr & $-0.307 * *$ & $0.016 \mathrm{~ns}$ & $0.146 \mathrm{~ns}$ & $-0.130 \mathrm{~ns}$ & $0.161 \mathrm{~ns}$ & $0.237 *$ & $0.546 * * *$ & $-0.013 n s$ \\
\hline & H'Fl & E Fl & H' Fr & E Fr & FM Fl & FM Fr & IM FI & IM Fr \\
\hline \multicolumn{9}{|l|}{ Glomus $\mathrm{Fl}$} \\
\hline \multicolumn{9}{|l|}{ AcaulosporaFl } \\
\hline \multicolumn{9}{|l|}{ GigasporaFl } \\
\hline \multicolumn{9}{|l|}{ ScutellosporaFl } \\
\hline \multicolumn{9}{|l|}{ Glomus Fr } \\
\hline \multicolumn{9}{|l|}{ Acaulospora Fr } \\
\hline \multicolumn{9}{|l|}{ Gigaspora Fr } \\
\hline \multicolumn{9}{|l|}{ Scutellospora Fr } \\
\hline H'Fl & 1 & & & & & & & \\
\hline $\mathrm{EFl}$ & $0,965 * * *$ & 1 & & & & & & \\
\hline $\mathrm{H}^{\prime} \mathrm{Fr}$ & $0.151 \mathrm{~ns}$ & $0.092 \mathrm{~ns}$ & 1 & & & & & \\
\hline E Fr & $0.022 \mathrm{~ns}$ & $-0.013 n s$ & $0.975 * * *$ & 1 & & & & \\
\hline FM Fl & $0.124 \mathrm{~ns}$ & $0.128 \mathrm{~ns}$ & $0.263 *$ & $0.218 \mathrm{~ns}$ & 1 & & & \\
\hline FM Fr & $0.287 *$ & $0.309 * *$ & $0.305^{* *}$ & $0.262 *$ & $0.801 * * *$ & 1 & & \\
\hline IM Fl & $-0.078 n s$ & $-0.093 n s$ & $0.291 *$ & $0.270 *$ & $0.776 * * *$ & $0.558 * * *$ & 1 & \\
\hline IM Fr & $0.233 *$ & $0.256 *$ & $0.231 *$ & $0.192 \mathrm{~ns}$ & $0.676 * * *$ & $0.879 * * *$ & $0.527 * * *$ & 1 \\
\hline
\end{tabular}

Fl : Flowering, Fr : fruiting, H' : Shannon-Weiner diversity index, E: Pielou equitability index, IM : Intensity of mycorrhization, FM : Frequency of mycorhization, $*$ : significant difference, ${ }^{* *}$ : highly significant difference, ${ }^{* * *}:$ very high significant difference, ns : non-significant.

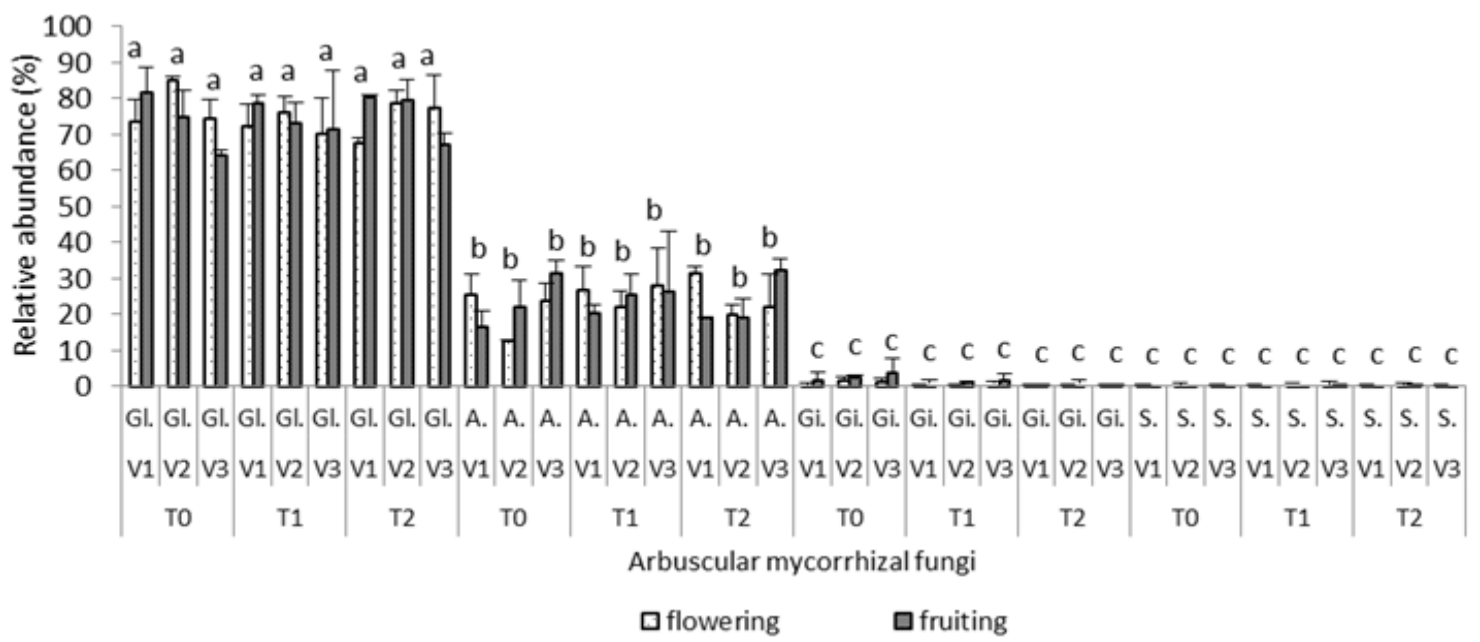

Fig. 6: AMF species relative abundance from Cucurbitaspp. under fertilizer application in Benin.Gl: Glomus; A: Acaulospora; Gi: Gigas pora; S: Scutellospora. V1 : Cucurbita maxima ; V2 : Cucurbita moschata elongated shape ; V3 : C. moschata egg-shaped ; T0 : control ; T1 : fowl droppings ; T2 : chemical fertilizers. For each growth stage, the means with the same letter are not significantly different at $\mathrm{p}<0.05$. 


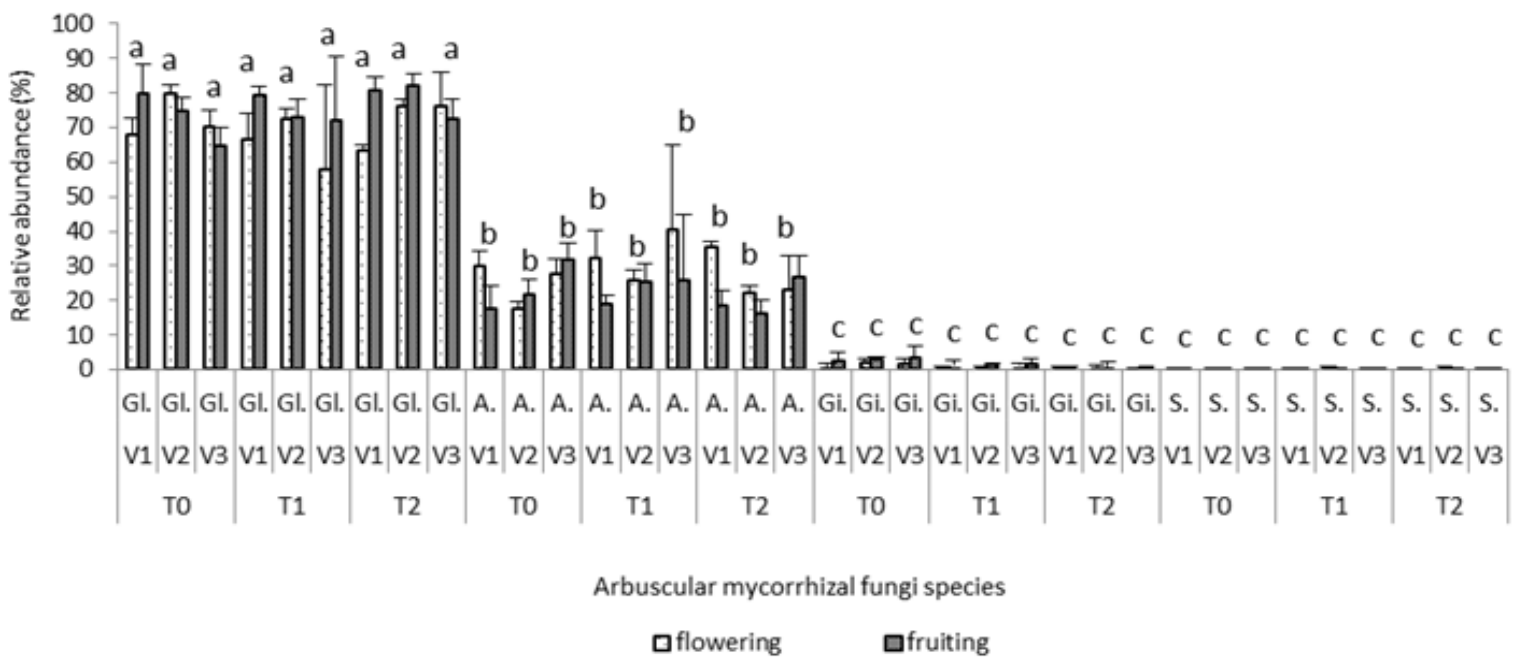

Fig. 7: AMF species relative abundance from Cucurbita spp under fertilizer application in Cameroon.Gl: Glomus; A: Acaulospora; Gi: Gigaspora; S: Scutellospora. V1 : Cucurbita maxima ; V2 : Cucurbita moschata elongated shape ; V3 : C. moschata egg-shaped ; T0 : control ; T1 : fowl droppings ; T2 : chemical fertilizers. For each growth stage, the means with the same letter are not significantly different at $\mathrm{p}<0.05$.

\subsection{Specific richness and diversity indices}

The specific richness, Shannon-Weiner (H') diversity index and Pielou (E) equitability index are higher in Cameroon than in Benin (Table 4). AMF are less diversified in Benin both at flowering and fruiting. Chemical fertilizer reduces the diversity of AMF.

In Cameroon at flowering, Shannon-Weiner index of variety 3 is significantly $(\mathrm{p}<0.05)$ low for $\mathrm{T} 2 \quad(1.85 \pm 0.14 \mathrm{bc})$ compared to T0 $(2.45 \pm 0.20 \mathrm{a})$ and T1 $(2.14 \pm 0.35 \mathrm{ab})$. ShannonWeiner diversity index and Pielou equitability index are strongly correlated $(\mathrm{p}<0.001)$ both at flowering and fruiting (Table 5). At flowering, the number of spores of the genera Glomus ( $\mathrm{p}<0.001$ ) and Scutellospora $(\mathrm{p}<0.05)$ are correlated to these two indices. The number of spore of the genera Glomus $(\mathrm{p}<0.001)$ and Gigaspora $(\mathrm{p}<0.05)$ are correlated to these indices at fruiting (Table 5).

\subsection{Relative Abundance of AMF}

The spores of Glomus (57.97-85.65\%) and Acaulospora (12.68-40.42\%) are more abundant than those of Gigaspora (0.24$3.93 \%)$ and Scutellospora (0.07-0.82 \%) in the two study sites. In fact, spores of Glomus constrictum, G. geosporum and Acaulospora lacunosa are more abundant in the two sites (Figure 6 and 7, Table 5). Hierarchical ascending classification (CAH) regroups the types of fertilizer in statistically homogenous classes on the basis of the number of AMF spores isolated from the rhizosphere of pumpkins (Figure 8). The hypothesis tested through this analysis is that the specific composition of endomycorrhizae in the sites helped to discriminate the fertilizers. Analysis of the dendrogramme shows two classes at a distance of $\mathrm{R}^{2}=0.63$ (Figure 8). The first class is made of two fertilizers, the nonfertilized control (T0) and fowl droppings (T1). The chemical fertilizer (T2) constitutes the second class.

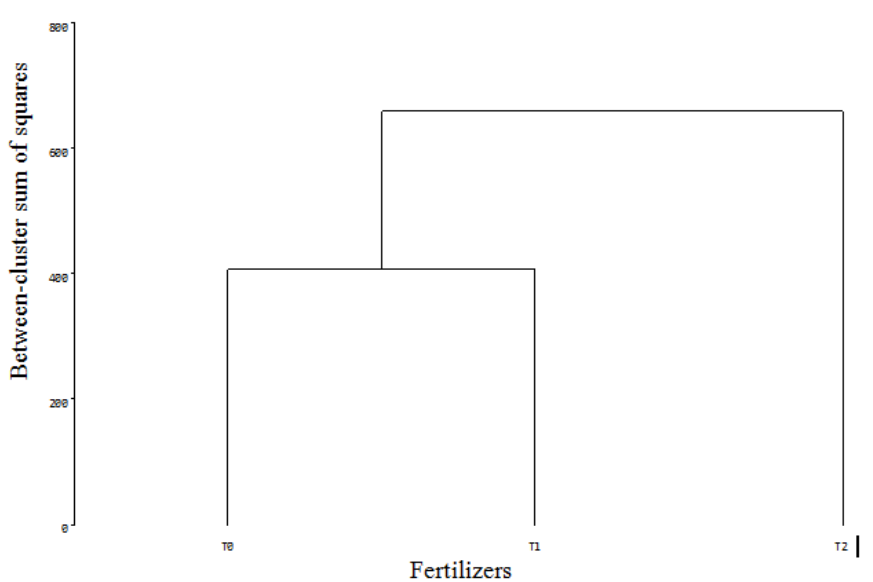

Fig. 8: Dendrogram showing the clustering of fertilizers based on presence of AMF morphotypes associated with rhizosphere soil of Cucurbita spp. in Benin and Cameroon. T0 : control ; T1 : fowl droppings; T2: chemical fertilizers.

\section{DISCUSSION}

The soil from Benin experimental site is slightly acidic (pH 6.06) while that in Cameroon is acidic ( $\mathrm{pH} 4.90)$ in reference to the Canadian information system on soils 24. Interpretation of the effect of $\mathrm{pH}$ on the population of AMF is very difficult, since a majority of chemical properties of the soil change with variations of soil $\mathrm{pH}$ 25. The soil of Abomey-Calavi (Benin) is poor in nitrogen contrary to the soil in Mbalgong (Cameroon). According to 26 , a soil is poor in nitrogen if the quantity of total $\mathrm{N}$ is less than $0.75 \mathrm{~g} / \mathrm{kg}$. A ratio of $\mathrm{C} / \mathrm{N}$ greater than 25 can block any mineralization process without external input of nitrogen 27. Low $\mathrm{C} / \mathrm{N}$ ratios in the two study sites indicate a rapid decomposition of organic matter. It leads to a poor functioning of the clay-humic complex. Chemical analysis also shows that these soils are deficient in organic matter. 
Chemical fertilizer significantly reduces the frequency and intensity of mycorrhization. Its application certainly increased soil acidity. Extreme soil acidity could be the cause of low proportions of spores observed in certain AMF species 28. Studies by 29 have shown that in the long run, chemical fertilizer application leads to reduction of the total number of AMF spores. They observed that only Acaulospora sp. of the nine species sampled on maize maintained its spore number with fertilizer application. This species has been classified as being insensitive to chemical fertilizer application. On the contrary, these workers noticed that the absolute number of Glomus sp. and G. geosporum diminished in response to fertilizer application; but not their relative abundance. Glomus sp. and G. geosporum were classified as being slightly sensitive to fertilizer application 29. Results obtained in this study show that Glomus is insensitive, Acaulospora slightly sensitive, Gigaspora and Scutellospora very sensitive to chemical fertilizer application. Contrary to chemical fertilizer, fowl droppings (organic fertilizer) did not reduce the frequency of mycorrhization by AMF in soil under pumpkin culture.

Fowl droppings had a mycorrhization frequency similar to that of the control without fertilizer. The hierarchical classification diagram shows two classes of fertilizer; one constituted of the control and fowl droppings and the other constituted of chemical fertilizer. These results corroborate with those of 30 who found that fungal communities of the soil are less influenced by application of compost from domestic waste. The results are equally similar to those of 31 . These workers found that the use of natural phosphate (rock phosphate) is more efficient in mycorrhized jujubes (Ziziphus jujube) compared to the control. In fact, organic fertilizers positively influence physical properties of the soil as compared to chemical fertilizers 32 . Soil amendment with organic fertilizers have shown increase of the activity 33, diversity 34 and soil microbial biomass 35 . Some workers 36 have also observed that cotton, maize and soya bean farms fertilized with organic matter present higher specific richness of AMF.

The present study has put into evidence the fact that soils on which pumpkin is cultivated both in Benin and Cameroon show a high diversity of AMF (15 species). This result is similar to those obtained by 37 working on 15 species in the north of Tibet. These 15 species identified under pumpkin culture were grouped into four genera (Glomus, Acaulospora, Gigaspora and Scutellospora). However, the culture conditions for pumpkin certainly favour the genus Glomus and Accaulospora as well as adaptation of species such as Glomus constrictum and Acaulospora lacunosa. The latter seem to be more competitive than the other species vis-à-vis pumpkins. In fact, the genus Glomus is considered as the most abundant of all the AMF in the tropical arid zone 38. The Acaulospora species are usually associated with acid soils 39 . They are adapted to a wide range of soils at different levels of nutrient availability 40 . This could justify their abundance in the two study sites. The predominance

of the Glomus and Acaulospora genera in the tropical zone seem to be due to their high competitiveness and to adaptation which permits them to be better established than the other genera of AMF in tropical conditions 41 . This could equally be due to the fact that their developmental cycle is not affected by repetition of cultures on the soils as compared to the minority genera such as Gigaspora and Scutellospora 17. The genera Glomus and Acaulospora are propagated more by spores which constitute a form of resistance of AMF in difficult conditions while the genera Gigaspora and Scutellospora are propagated more by the other types of propagules such as hyphae, and mycelial fragments on root surfaces 18 .

The production of AMF spores vary significantly with different ecosystems. It can be influenced by various factors such as environment, host species, the fungus and the density of spores which tends to diminish during root growth but increases during inactivity or senescence of roots 42 . A low difference in specific richness was observed in the two study sites. Glomus intraradices was absent in Benin and present in Cameroon. The difference in physicochemical properties in the two soils could justify this result. In fact, the irregular spatial distribution of AMF spores and the complex structure of the rhizospheric constituents affect density of spores 43 . Both at flowering and fruiting, the values of Shannon-Wiener index are lowest in the plots treated with chemical fertilizer. In the two sites, average values of ShannonWiener index vary from 1.41 to 2.47 . This result is similar to those of 44 who observed an index in the order of 2.3 in the tropical forest. Cucurbita moschata ovoid form (2.04) and C. moschata elongated form (1.90) had Shannon-Weiner index values higher than that of C. maxima (1.85). The diversity of AMF under pumpkin culture seems to be influenced by the plant's genotype.

The study highlighted the predominance of Glomus and Acaulospora genera in pumpkin rhizosphere. The genera Glomus and Acaulospora are more appropriate for the preparation of inocula for pumpkin cultivation in the study sites (Benin and Cameroon). For sustainable production of pumpkins, these fungi can be isolated, purified, multiplied and used as organic fertilizer without necessarily being associated with the chemical fertilizers.

\section{CONCLUSION}

The objective of this study was to assess the biodiversity of arbuscular mycorrhiza fungi (AMF) associated with pumpkin culture under the effect of fertilizers in Cameroon and Benin. Chemical fertilizer reduced the frequency and intensity of mycorrhization but not the specific diversity. On the basis of number of spores observed, the hierarchical classification diagram shows two classes of fertilizer. The control and fowl droppings constitute the first class while chemical fertilizer constitutes the second class. In these soils, four genera of AMF (Glomus, Acaulospora, Gigaspora and Scutellospora) constituting 15 species were recorded. The genera Glomus and Acaulospora and particularly Glomus constrictum, G. geosporum and Acaulospora lacunosa are specific to pumpkins in the two sites.

\section{ACKNOWLEDGEMENTS}


The authors express their acknowledgement to the European Commission for funding the study through the IntraAfrican Program of Academic Mobility (PIMASO). We are also thankful to the institutions and laboratories that hosted the work.

\section{REFERENCES}

1. CIRAD. Fruits et légumes, la santé du monde. Montpellier, février 2009, CIRAD. 16 p.

2. Palm CA, Myers RJK \& Nandwa SM. Combined use of organic and inorganic nutrient sources for soil fertility maintenance and replenishment. In: Buresh, R.J., Sanchez, P.A., and Calou F. (Eds.). Replenishing soil fertility in Africa. USA. Soil Sci. Soc. Am. (SSSA). 1997; 51: 120-125.

3. de Carvalho LMJ, Gomes PB, de Oliveira Godoy RL, Pacheco S, do Monte Pedro HF, de Carvalho JLV, Nuttib MR, Neves ACL, Vieira ACRA \& Ramos SRR. Total carotenoid content, $\alpha$-carotene and $\beta$ carotene of landrace pumpkins (Cucurbita moschata Duch): A preliminary study. Food Research International. 2012; 47: 337-340.

4. Chigumira NF \& Grubben GJH, Cucurbita maxima Duchesne. In: Grubben GJH \& Denton OA (eds.); PROTA 2: Vegetables/Légumes. PROTA, Wageningen, Pays Bas; 2004.

5. Dodd JC. The role of arbuscular mycorrhizal fungi in agro and natural ecosystems. Agricul. 2000; 29 (1): 63-70.

6. Gianinazzi S, Gianinazzi-Pearson V, \& Trouvelot A. Les mycorhizes, partie intégrante de la plante : biologie et perspective d'utilisation. Coll. INRA, No 13, INRA, Paris. 1982.

7. Harley JL \& Smith SE. Mycorrhizal symbiosis. Academic Press Inc, London; 1983.

8. Janos DP. Heterogeneity and scale in tropical vesicular-arbuscular mycorrhiza formation. In: Mycorrhizas in ecosystems. Read DJ, Lewis DH, Fitter AH \& Alexander IJ (Eds.). CAB Int. 1992; $276-$ 282.

9. Yadi S. Mycorrhizal inoculum production technique for land rehabilitation. Jurnal Manajemen Hutan Tropika. 2002; 8 (1): 51-64.

10. Miyasaka SC, Habte M, Friday JB, \& Johnson EV. Manual on Arbuscular Mycorrhizal Fungus Production and Inoculation Techniques. Soil and Crop Management, SCM-5. 2003; 1-4.

11. Ngonkeu MEL. Biodiversité et potentiel des mycorhizes à arbuscules de certaines zones agro-écologiques du Cameroun. Thèse de Doctorat 3e cycle, Université de Yaoundé I. 2003; 258 p.

12. Onguene AN \& Kuyper. Diversity and abundance of mycorrhizal association in the rain forest of South Cameroon. Tropenbos Cameroon Programme. Forest Ecology Management. 2001; 140: 277-287.

13. Gianquinto $\mathrm{G} \&$ Borin $\mathrm{M}$. Effect of organic and mineral fertilizer application and soil type on the growth and yield of processing tomatoes (Lycopersicon esculentum Mill.). Rivista di Agronomia. 1990; 24 (4): 339-348.

14. Phillips JM \& Haymann DS. Improved procedures for clearing roots and staining parasitic and vesicular-arbuscular mycorrhizal fungi for rapid assessment of infection. Transactions of the British Mycological Society. 1970; 55: 157-160.

15. Gendermann JW \& Nicholson TH. Spores of mycorrhizal endogone species extracted from soil by wet sieving and decanting. Trans. Br. Mycol. Soc. 1963; 46: 235-244.

16. Daniels BA \& Skipper HD. Methods for the recovery and quantitative estimation of propagules from soil. $I n$ : Schenck, N. C. (ed). Principles and methods of mycorrhizal research. The St Paul Minn, American Phytopathological Society, USA, 1982; p. 29-36.

17. Oehl F, Sieverding E, Ineichen K, Mader P, Boller T \& Wiemken A. Impact of land use intensity on the species diversity of arbuscular mycorrhizal fungi in agroecosystems of central Europe. Applied Environmental Microbiology. 2003; 69: 2816-2824.

18. Brito I, Goss MJ, de Carvalho M, Chatagnier O \& van Tuinen D. Impact of tillage system on arbuscular mycorrhiza fungal communities in the soil under Mediterranean conditions. Soil and Tillage Research. 2012; 121: 63-67.

19. Josserant M. La description des champignons supérieurs. Editions le chevalier, Paris, France; 1983, 392 p.

20. Dandan Z \& Zhiwei Z. Biodiversity of arbuscular mycorrhizal fungi in the hot-dry valley of the Jinsha River, southwest China. Applied Soil Ecology. 200; 37: 118-128.

21. Shannon CE. A mathematical theory for communication. Bell Syst. Tech. J. 1948; 27: 379-423 \& 623-656.

22. Pielou EC. The measurement of diversity in different types of biological collections. J. Theor. Biol. 1966; 13: 131-144.

23. Schüßler A, Schwarzott D \& Walker C. A new fungal phylum, the Glomeromycota: phylogeny and evolution. Mycological Research. 2000; 105: 1413-1421.

24. Lamontagne L \& Nolin MC. Dossier des noms de sols du Québec 1997. SISCan (Système d'Information des Sols du Canada). Equipe pédologique du Quebec, Centre de recherches et de développement sur les sols et les grandes cultures, Agriculture et Agroalimentaire Canada (Sainte-Foy).

25. Bagyaraj DJ. Ecology of vesicular arbuscular mycorrhizae. In: Arora D. K., Rai B., Mukerji K. G., Knudsen G. R. (Eds.), Handbook of applied mycology: soil and plants. Marcel Dekker, Inc., New York, 1991; pp. 3-34.

26. Baize D. Guide des analyses en pédologie: choix-expressionprésentation interprétation. 2ème édition. INRA, Paris. 2000; 257 p.

27. Boyer J. Les sols ferralitiques. Vol. X. Facteurs de fertilité et utilisation des sols. Paris: Orstom, 1982.

28. Bivoko D-RR, Ahonzo-Niamke SL \& Zeze A. Impact des propriétés physicochimiques des sols de culture du manioc sur l'abondance et la diversité des communautés de champignons mycorhiziens à arbuscules dans la zone agroécologique d'Azaguie, sud-est de la côte d'ivoire. Agronomie Africaine. 2013; 25 (3): 251-264.

29. Bhadalung NN, Suwanarit A, Dell B, Nopamornbodi O, Thamchaipenet A \& Rungchuang J. Effects of long-term NPfertilization on abundance and diversity of arbuscular mycorrhizal fungi under a maize cropping system. Plant and Soil. 2005; 270 (12): $371-382$

30. Leyval C, Steinberg C, Norini MP, Beguiristain T, Edel-Hermann V, Leglize $\mathrm{P}$, Gautheron $\mathrm{N}$, Lebeau $\mathrm{T}$ \& Houot $\mathrm{S}$. Impact d'amendements organiques sur la structure des communautés microbiennes des sols : Choix des méthodes, validation et résultats. Étude et Gestion des Sols. 2009; 16: 299-312.

31. Guissou T, Bâ AM, Guinko BS, Duponnois R \& Plenchette C. Influence des phosphates naturels et des mycorhizes à vésicules et à arbuscules sur la croissance et la nutrition minérale de Zizyphus mauritiana Lam. dans un sol à pH alcalin. Ann. Sci. For. 1998; 55: 925-931.

32. Celik I, Ortas I \& Kilic S. Effects of compost, mycorrhiza, manure and fertilizer on some physical properties of a Chromoxerert soil. Soil and Tillage Research. 2004; 78: 59-67.

33. Liu B \& Ristaino JB. Microbial community structure in soils from organic and conventional agroecosystems. Phytopathology. 2003; 96 S53.

34. Girvan MS, Bullimore J, Ball AS, Prett, JN \& Osborn AM. Responses of active bacterial and fungal communities in soils under winter wheat to different fertilizer and pesticide regimens. Applied \& Environmental Microbiology, 2004; 70: 2692-2701

35. Okur N, Altindisli A, Cengel M, Gocmez S \& Kayikcioglu HH. Microbial biomass and enzyme activity in vineyard soils under organic and conventional farming systems. Turkish Journal of Agriculture \& Forestry. 2009; 33:413-423.

36. Sousa C, da S, Menezes RSC, Sampaio EVm de SB, Oehl F, Costa Maia L, Garrido M, da S, Lima F \& de S. Occurrence of arbuscular mycorrhizal fungi after organic fertilization in maize, cowpea and cotton intercropping systems. Acta Sci. Agron. 2012; 34 (2).

37. Peng YL, Yang MN \& Cai XB. Influence of soil factors on species diversity of arbuscular mycorrhizal (AM) fungi in Stipa steppe of Tibet plateau. Ying Yong Sheng Tai XueBao. 2010; 21 (5): 1258-63. 
38. Maksoud MA, Haggag LF, Azzazy MA \& Saad RN. Effect of VAM inoculation and phosphorus application on growth and nutrient content (P and $\mathrm{K}$ ) of Tamarindus indica L. Seedlings. Ann. Afric. Sci. Caito. 1994; 39: 355-363.

39. Abbott LK \& Robson AD. Factors influencing the occurrence of vesicular-arbuscular mycorrhizas. Agriculture, Ecosystem and Environment. 1991; 35: 121-150.

40. Straker CJ, Hilditch AJ \& Rey MEC. Arbuscular mycorrhizal fungi associated with cassava (Manihot esculenta Crantz). South African Journal of Botany. 2010; 76: 102-111.

41. Singh S, Pandey A, Chaurasia B \& Palni LMS. Diversity of arbuscular mycorrhizal fungi associated with the rhizosphere of tea growing in 'natural' and 'cultivated' ecosites. Biology and Fertility of Soils. 2008; 44: 491-500.

42. Muthukumar T, Sha LQ, Yang XD, Cao M, Tang JW \& Zheng Z. Mycorrhiza of plants in different vegetation types in tropical ecosystems of Xishuangbanna, southwest China. Mycorrhiza. 2003; 13: 289-297.
43. Zhao ZW, Xia, YM, Qin, XZ, Li, XW, Cheng, LZ, Sha T \& Wang $\mathrm{GH}$. Arbuscular mycorrhizal status of plants and the spore density of arbuscular mycorrhizal fungi in the tropical rain forest of Xishuangbanna, southwest China. Mycorrhiza. 2001 ; 11: 159-162.

44. Husband R, Herre EA, \& Young JPW. Temporal variation in the arbuscular mycorrhizal communities colonizing seedlings in a tropical forest. FEMS Microbiology Ecology. 2002; 42: 131-136.

\section{How to cite this article:}

Judith Taboula Mbogne, Carine Nono Temegne, Pascal Hougnandan, Emmanuel Youmbi, Libert Brice Tonfack, Godswill Ntsomboh-Ntsefong. Biodiversity of arbuscular mycorrhizal fungi of pumpkins (Cucurbita spp.) under the influence of fertilizers in ferralitic soils of Cameroon and Benin. J App Biol Biotech. 2015; 3 (05): 001-010. DOI: 10.7324/JABB.2015.3501 